\title{
BIBLIOTECA PÚBLICA, O PROTAGONISMO NA FORMAÇÃO DE LEITORES.
}

*Maria de Lurdes Teles de Aguiar

RESUMO: A biblioteca pública é uma porta de acesso ao conhecimento que ajuda a fornecer as condições básicas para a aprendizagem ao longo da vida, promovendo o desenvolvimento cultural do indivíduo e dos grupos sociais a caminho da cidadania. A ausência de bibliotecas impede a formação de sujeitos-leitores, quando saem da escola ao invés de continuarem a buscar a leitura e efetivarem-se como leitores, acaba por afastá-los, criando neles um afastamento da leitura. Buscou-se aqui através de uma pesquisa bibliográfica exploratóriodescritiva descrever o tema em seus aspectos históricos e legais, enfatizando a importância da leitura e do livro, destacando a necessidade de implementação das políticas públicas de apoio direcionadas a criação, reforma e manutenção de bibliotecas públicas.

Palavras-Chave: Biblioteca Pública, Leitura, Cidadania.

ABSTRACT: The public library is a gateway to knowledge that helps provide the basic conditions for lifelong learning, promoting the cultural development of individuals and social groups on the way to citizenship. The absence of libraries prevents the formation of subjectreaders, when they leave school instead of continuing to seek reading and become effective as readers, it ends up alienating them, creating a distance from reading in them. An exploratorydescriptive bibliographic search was sought here to describe the theme in its historical and legal aspects, emphasizing the importance of reading and the book, highlighting the need to implement public support policies aimed at the creation, reform and maintenance of libraries public.

Keywords: Public Library, Reading, Citizenship.

RESUMEN: La biblioteca pública es una puerta de entrada al conocimiento que ayuda a proporcionar las condiciones básicas para el aprendizaje permanente, promoviendo el desarrollo cultural de individuos y grupos sociales en el camino hacia la ciudadanía. La ausencia de bibliotecas impide la formación de lectores de asignaturas, cuando abandonan la escuela en lugar de continuar buscando la lectura y se vuelven efectivos como lectores, termina alienándolos, creando una distancia de la lectura en ellos. Se buscó aquí una búsqueda bibliográfica descriptiva exploratoria para describir el tema en sus aspectos históricos y legales, enfatizando la importancia de la lectura y el libro, destacando la necesidad de implementar políticas de apoyo público dirigidas a la creación, reforma y mantenimiento de bibliotecas. público

Palabras clave: Biblioteca Pública, Lectura,

*Maria de Lurdes Teles de Aguiar é doutora especialista em Ciências da Educação.

E-mail para contato: mjaguiartransporte@yahoo.com.br 


\section{INTRODUÇÃO}

A biblioteca pública é fonte de conhecimento e informação que proporciona desenvolvimento intelectual e social promovendo ainda a difusão da cultura local. A era da comunicação eletrônica, induz que para qualquer informação necessária, buscam-se textos na internet. Porém, por mais valioso e prático que seja esse instrumento, ele não pode e não deve ser a única fonte de conhecimento. Uma biblioteca bem equipada nunca perderá terreno para textos superficiais, mal elaborados e em muitos casos equivocados que temos na web. Para um conhecimento completo, abrangente, definitivo, um bom livro é fundamental.

O manifesto da UNESCO aprovado na carta de Paris em 1994 declara a biblioteca púbica, em todos os países, como "instituições essenciais para promoção da paz da humanidade". Esse enunciado nos faz crer que a biblioteca pública é um direito da comunidade, assim como o acesso à informação e à apropriação do conhecimento. E, mais ainda, a biblioteca pública, como diz o manifesto, é a "porta de entrada para o conhecimento", e são missões desta "a informação, alfabetização, educação e cultura, devendo estar impressas na essência dos serviços da biblioteca pública".

Portanto, entende-se que há uma relação entre o que diz a missão da biblioteca pública: oferecer serviços com base na disseminação da informação, cultura e do conhecimento e o que diz a ciência da informação ao estudar a relação entre a informação e o conhecimento, ou a informação geradora de conhecimento. O papel social da Biblioteca Pública é permeado pelo acesso e disponibilidade da informação. A relação entre esta informação e o conhecimento é observada sob a ótica da Ciência da Informação a partir de 1980 (BARRETO, 2007, p. 25).

A geração de conhecimento é uma reconstrução das estruturas mentais do indivíduo realizado através de sua competência cognitiva, ou seja, é uma modificação em seu estoque mental de saber acumulado, resultante de uma interação com uma forma de informação (BARRETO, 2007, p. 27).

Para que a sociedade possa usufruir da desejável democracia e igualdade de oportunidades dentro de um processo de aprendizagem, a biblioteca pública deve ser de fácil acesso, estando aberta a todos os membros da comunidade, sem distinção de idade, raça, sexo, religião, estado social, deficiência física, nacionalidade e grau de instrução. Seus serviços e recursos devem, portanto, basear-se na igualdade de acesso, sendo projetados conforme as necessidades dos seus usuários. Desta forma, deve constituir-se em um ambiente verdadeiramente público onde as pessoas possam, além de buscar sanar suas necessidades de 
informação, se encontrar para conversar, discutir problemas e participar de atividades culturais e de lazer (MINUTZZO, 2004, p.27).

É preciso lembrar que organizar uma biblioteca púbica para atender as futuras demandas que se seguem requer uma análise cuidadosa das condições e necessidades da comunidade ao qual se destina. Estar atento às atividades e serviços presentes e futuros, da biblioteca, é indispensável. Nesse sentido, a observância dos aspectos de acessibilidade, espaços de convivência, utilização de cores adequadas, material eficaz, espaços adequados para aprendizagem, conforto ambiental, iluminação adequada etc., além de questões de acervo fazem parte da preocupação em ter e montar uma boa biblioteca.

\section{BIBLIOTECAS, CONCEITO, TIPOLOGIA E HISTÓRIA.}

Pensar em uma biblioteca que seja um espaço congruente com as demandas contemporâneas em um país, onde os dramas do analfabetismo, da evasão escolar e de tantas outras mazelas sociais são gritantes, são corriqueiros é mister utópico. Para entender um pouco da conceituação e história da escrita, dos livros, das primeiras bibliotecas, entendendo-as a princípio como centros de difusão de saber mas de demonstração de poder e status quo, buscouse uma fundamentação com autores que tratam do tema sob o ponto de vista histórico mas procurou-se também enfatizar a importância da leitura e da escrita para o desenvolvimento humano.

Assim se apresentará aqui um histórico sobre a origem das bibliotecas, seu conceito, e os diferentes tipos de biblioteca encontrados. Esse entendimento torna-se necessário para que a interligação entre a concepção sócio histórica, econômica, cultural seja base para a percepção da concepção arquitetônica das bibliotecas através do tempo.

O surgimento das bibliotecas remonta à origem da palavra escrita, quando ainda eram utilizadas no seu sentido semântico enquanto depósito de livros, significado esse do vocábulo grego bibliotheke, por isso era entendida como o depósito responsável pela guarda de materiais escritos, papiros e pergaminhos (SCHWARCZ, 2002).

Apesar de atualmente significar muito mais que um depósito de livros, a palavra utilizada para designa-la não mudou através do tempo, mudando apenas as diversas formas e estilos de biblioteca existentes.

Sempre marcada pelas nuances sócio culturais, a biblioteca representa também a concepção de vida, de mundo e não deixa também de expor uma concepção de poder visto que o conhecimento é também uma forma de representação desse. Assim, o acesso á biblioteca era algo dado somente àqueles que disponibilizavam do instrumento que diferenciava e separava 
as pessoas através dos tempos: o acesso à leitura.

De acordo com (SANTOS, 2016), desde sua concepção subjetiva até a sua concepção arquitetônica, a restrição era a palavra de ordem no que se refere à biblioteca. A imponência no seu aspecto físico escondia a real intenção de sua feitura que era além de impedir o acesso de grande parte das pessoas, impedir também a circulação e popularização dos livros.

Francis Bacon (1561) filósofo e ensaísta inglês já dizia que conhecimento é em si mesmo o poder. Esta frase tão repercutida demonstra a força que a palavra escrita e a leitura podem ter numa sociedade praticamente iletrada como a europeia e de onde se difundia a ciência e o conhecimento para o resto do mundo. A leitura palavra derivada do Latim "lectura", originalmente com o significado de "eleição, escolha, ou seja, literalmente esse acesso, essa escolha representava o acesso ao poder e, portanto, não seria para todos.

Conforme (MANGUEL; GUADALUPE, 2003), na Antiguidade e na Idade Média a projeção das entradas das bibliotecas possuía guardas para impedir a circulação e roubo das obras, existiam portas que não levavam a lugar algum, corredores sem saída, entradas e saídas falsas, que eram fingimentos, enfim, tínhamos um real labirinto no qual poucos entravam e saíam impunes.

Aqui há que se recordar que os livros eram extremamente caros, manuscritos, poderiam levar anos sendo escritos. De acordo com VERGER (1999) o fator principal do elevado preço dos livros era o custo da cópia. Os bons copistas eram raros. No final da Idade Média, os scriptoria monásticos haviam perdido o essencial de sua importância e a maior parte dos escribas seriam, doravante, artesãos profissionais que se encontravam principalmente em grandes cidades, especialmente aquelas que abrigavam uma clientela importante, quer dizer, as capitais da nobreza e as cidades universitárias.

Mesmo os melhores copistas trabalhavam lentamente escreviam por volta de duas folhas e meia por dia, em média. Por outras palavras, em um ano, um bom copista produzia apenas cinco livros de duzentas folhas; ou ainda, se preferirmos, para chegar a fornecer mil livros deste tipo em um ano, não se poderia ter menos de duzentos copistas trabalhando o tempo inteiro.

Nas cidades universitárias, onde havia necessidade de muitos livros, e onde os recursos financeiros eram limitados, procurou-se reduzir a um mínimo o preço de revenda dos livros: pequenos formatos, linhas apertadas, escrita mais cursiva, multiplicação das abreviaturas permitiam economizar o pergaminho ou o papel, sempre ganhando um pouco de tempo de cópia (VERGER,1999).

Com a adoção do sistema de pecia, que apareceu em Bolonha e em Paris durante o século XIII, acelerou-se a rotação dos exemplares a serem reproduzidos, permitia igualmente 
melhorar a produtividade dos escribas, sempre preservando a qualidade dos textos postos em circulação. Consistia esse, em confiar aos livreiros da universidade exemplares oficialmente controlados dos principais livros de estudo; tais exemplares eram feitos de cadernos (pecioe) não ligados, o que permitia serem alocados para inúmeros copistas ao mesmo tempo; estes podiam, então, produzir simultaneamente muitas cópias do mesmo livro.

Ainda de acordo Verger (1999), a contratação de copistas amadores foi a solução encontrada para desonerar o preço dos livros, mas ainda assim, as condições para tê-los não eram acessíveis, pois o acesso à educação também não era acessível. Por esse motivo, sinal de ostentação e demonstração de poder e importância eram possuir um acervo de livros, ou uma biblioteca particular, possibilidade geralmente dada aos nobres, ao Clero, ao Parlamento e a alguns mestres mais ricos.

$\mathrm{Na}$ Idade Média possuir um livro significava literalmente possuir um tesouro e como qualquer tesouro precisa de local apropriado para a acomodação.

\begin{abstract}
Entre os próprios homens de saber, as coleções de livros possuíam importância variável. A biblioteca de um estudante, ainda que abastado, não ultrapassava praticamente, em média, uma dúzia de volumes: os livros de estudos fundamentais, de um lado, uma ou duas coleções de textos religiosos, de outro. Seus professores, que tinham necessidade de uma pequena biblioteca pessoal para preparar seus cursos, eram um pouco melhor aquinhoados e possuíam, para além das "autoridades" de base, um determinado número de comentários e tratados modernos; isso representava, no mínimo, cerca de trinta livros. Contudo, alguns mestres, mais ricos ou de espírito mais curioso, possuíam bibliotecas que alcançavam ou até ultrapassavam uma centena de volumes. (VERGER,1999, p.13).
\end{abstract}

Assim, entre os séculos XIV e XV em finais da Idade Média, era comum associar o padrão de vida das pessoas à quantidade de livros que possuíam e a partir daí o hábito de se montarem as bibliotecas particulares como parte do tesouro ou riqueza pessoal. O livro era, além de um referencial simbólico, conservados dentro de um cofre ou armário, os livros indicavam a formação intelectual de seu proprietário, representavam também um tesouro material, pois geralmente representava em valor, a metade ou mais do capital imobiliário, mas também o reconhecimento público da nobreza do seu saber e das atividades que ele exercia.

Por esse motivo, além da dimensão sócio cultural, a dimensão política e econômica delimitam os primórdios da biblioteca enquanto ideia e enquanto espaço físico. Assim as grandiosas e imponentes bibliotecas construídas representam a concepção social, cultural, política e econômica e até religiosa das sociedades que representam.

Desde a primeira do mundo erguida em Nínive, Assíria (atual Iraque), pelo rei Assurbanipal II, por volta do século 7 a.C. ( onde foram armazenadas milhares de tabuletas escritas com caracteres cuneiformes, a mais antiga forma de escrita que se conhece), até a 
soberba biblioteca de Alexandria no Egito, talvez a mais famosa do mundo antigo fundada no século 2 a.C., durante o reinado de Ptolomeu II, a biblioteca foi uma representação do poder. Essa última provavelmente possuiu mais de 700 mil volumes, abrangendo obras importantíssimas da Antiguidade, que desapareceram com o tempo e com os diversos incêndios e ataques que trouxeram seu fim definitivo no século I A.C.

Não obstante fato comum serem as primeiras locais a serem destruídos em casos de guerra, por se constituir a própria referência da história da população e dos povos conquistados. Em 2002, foi inaugurada uma grande biblioteca no mesmo local da antiga Biblioteca Alexandrina, como uma homenagem à primeira.

\subsection{A INVENÇÃO DA IMPRENSA E OS PRIMEIROS PASSOS PARA A ACESSIBILIDADE À LEITURA.}

As bibliotecas vão tornando-se mais comuns com o acesso ao livro. E isso só ocorre com a invenção da imprensa a partir de 1445 já na Idade Moderna. A tipografia permitiu que os textos, que eram antes manuscritos, fossem impressos a partir da elaboração dos tipos, letras móveis produzidas em cobre e colocadas em uma base de chumbo onde recebiam a tinta e eram prensadas no papel. Dessa forma, a imprensa, como ficou conhecida a elaboração de Gutemberg, passou a influenciar a produção e divulgação de conhecimento, contribuindo para um maior desenvolvimento não apenas da produção literária na Europa, mas de ramos como a metalurgia e da produção de papel.

A maioria dos historiadores afirma que o papel dessa invenção tem uma conotação muito maior do que a simples e mecânica reprodução das letras. O historiador francês Roger Chartier (1994), um dos grandes estudiosos da história do livro e da leitura, destacou que a invenção de Gutenberg foi tão revolucionária que só pode ser comparada atualmente à invenção do computador e da reprodução digital da escrita.

Muitas modificações ocorreram no mundo graças a este invento. Sob o ponto de vista social, ela revolucionou as classes, determinou o desaparecimento dos copistas e fez com que o movimento intelectual chegasse a nível inimaginável à época. Nesse momento histórico precisamente as elites de sangue são substituídas pelas intelectuais, que mais tarde vem redimensionar todo o mapa cultural europeu com o chamado Renascimento. Há uma efervescência de ideias, invenções e ao contrário da Idade Média onde eram escondidas, passaram a aparecer para o mundo e a imprensa certamente foi o canal facilitador para tal.

No período conhecido como Renascimento, e tendo a Bíblia como o primeiro dos livros 
inteiros publicados pela técnica da imprensa, a paulatina e gradual popularização da leitura, vai trazendo os antes inatingíveis livros a um contexto mais acessível, possibilitando que as bibliotecas antes privadas e distantes fossem ficando mais próximas da população, mas, nem de todos é claro.

Isso teve uma repercussão para a Igreja Católica que antes detentora do conhecimento e do saber, agora vê seu poderio ameaçado por essa acessibilidade que vai sendo proporcionada com os avanços promovidos pela popularização da Bíblia e dos livros, que influenciam fortemente na Reforma Protestante, outro divisor de águas na História Ocidental Moderna.

A Bíblia foi espalhada por toda parte, e isto deu margem a discussões em torno de sua interpretação, preparando a Reforma protestante em alguns espíritos. O livro baixou de preço, e então a cultura esteve ao alcance de qualquer bolsa. Também no terreno político e no econômico a influência foi grande. As ideias políticas e as experiências econômicas puderam ser através do livro e do jornal, conhecidas por todos. Desta expansão, profundas consequências deveriam surgir durante a idade moderna e contemporânea.

Assim, de acordo com OLIVEIRA (2014), as consequências da invenção e utilização da imprensa foram imensas, rapidamente se expandiu por toda a Europa. Em 1500, só na Itália, 54 cidades já possuíam tipografias, e assim a imprensa desenvolvia-se de maneira vertiginosa. As Universidades passaram a ter suas próprias tipografias e em 1470, G. Fichst, reitor da Universidade de Paris, montava uma tipografia da universidade. Nela trabalharam três ilustres impressores: Gering, Friberzert e Kaantz. Esta tipografia imprimiu em dois anos 21 trabalhos, clássicos de preferência.

\subsection{A IDÉIA DE BIBLIOTECA PÚBLICA NA PROMOÇÃO DA} UNIVERSALIZAÇÃO DO CONHECIMENTO.

A série de ocorrências que vão da invenção da imprensa à expansão do comércio, ao surgimento das novas rotas comerciais e as Grandes Navegações, que vão ao desenvolvimento das cidades, que oportunizam ao surgimento da burguesia e consequentemente de uma redefinição das necessidades da nova classe social, o redimensionamento da educação enfim, essa série de fatores. O período medieval que havia sido marcado pela existência de três tipologias básicas de bibliotecas: as monacais, as universitárias e as particulares (MARTINS, 2002), sendo as primeiras as principais desse período histórico, dão lugar agora na Idade Moderna para o advento das primeiras bibliotecas públicas.

Considerada a idade onde se aprofunda o ideal da democracia a partir das grandes 
revoluções históricas, a Idade Moderna, mais precisamente a partir do século XVI é quando começam a surgir as primeiras bibliotecas modernas, que segundo (MARTINS, 2002), apresentam quatro características fundamentais que se integram: laicização, democratização, especialização e a socialização.

\begin{abstract}
A biblioteca passa cada dia mais a responder novas necessidades e questões, tendo uma concepção voltada para uma constante democratização. A concepção de um depósito ou espaço onde a passividade impera não cabe mais dentro das proposições das comunidades e leitores modernos, penetrando em ambientes antes inimagináveis, tais como o assentamento rural, a favela ou a região em que moram os trabalhadores operários (MARTINS, 2002, p.45).
\end{abstract}

Assim, a democratização, e a diversidade do público de acesso trouxeram também a necessidade de diversificação quanto aos tipos de biblioteca, decorrente além da quantidade crescente da produção intelectual e a liberdade agora de exposição desses pensamentos, a especialização crescente, tornando cada vez mais difícil uma biblioteca única que atendesse a um público homogêneo.

Organismo antes reservado a uns poucos, que deviam procurá-la e solicitar-lhe os favores, a biblioteca moderna não apenas abriu largamente as portas, mas ainda sai à procura de leitores; não apenas quer servir ao indivíduo isolado, proporcionando-lhe a leitura, o instrumento, a informação de que necessita, mas ainda deseja satisfazer às necessidades do grupo, assumindo voluntariamente o papel de um órgão sobrecarregado, dinâmico e multiforme da coletividade. (MARTINS, 2002, p 34).

A partir desse momento histórico e frente às necessidades que se impunham a ideia de biblioteca enquanto espaço público passa a ser delimitada: a questão do livre acesso, fornecimento de serviços gratuitos e uma variedade de suportes informacionais integrando o acervo, são os pontos mais importantes a ser considerados para a sua idealização. (URIBE TIRADO, 2007).

Assim, o ideal de biblioteca moderna precisa ser um espaço de acesso e que possibilitasse uma equiparação nos saberes que possa facilitar a construção de uma sociedade justa, igualitária dentro dos pressupostos da modernidade. Mas não foi na Idade moderna que esse acesso começou em larga escala. Apenas no pós Iluminismo, pós Revolução Francesa e pós Revolução Industrial, com a propagação dos ideais democráticos agora postos em prática e saídos do campo das ideias, passam a incentivar o ideal de biblioteca pública.

Dessa forma a biblioteca pública é originalmente reconhecida como surgida em 1850 na Inglaterra, e apesar de motivada por todas as revoluções citadas acima, teve seu financiamento através do auxílio de magnatas na manutenção e subsidiamento dessas instituições em seu início, sendo grandes mantenedores delas. (ARRUDA 2000).

De acordo com Lemos (2005) essas empresas e conglomerados tinham sua concessão através de lutas sociais na busca de melhorias da qualidade educacional dos bairros pobres de 
países que vinham se consolidando como expoentes econômicos dos tempos modernos, apenas após muitas pressões dos trabalhadores é que no início do século XX alguns governos de alguns países como os Estados Unidos iniciam o repasse de verbas que subsidiam a existência dessas instituições.

\begin{abstract}
A biblioteca pública tem um caráter social e com base em uma regulação estatal, que permita o acesso aos mais diferentes suportes de informação, buscando sempre satisfazer as necessidades do público que pretende atender, adquirindo e separando materiais que tenham esse perfil, atuando sempre em um caminho de ajuda ao que os sujeitos-leitores necessitam, auxiliando na melhoria de vida dos mesmos (JARAMILLO; MONTOYA RÍOS, 2000,p.17).
\end{abstract}

Atualmente a quantidade de bibliotecas públicas no mundo está também relacionada à questão de poderes. Não aqueles individuais e hierárquicos de nobreza ou clero, mas com o poder político emanado do povo que quando leitor instrumentalizado detém o poder do conhecimento que pode transformar as vidas.

Os primeiros contatos dos brasileiros com a cultura letrada estão atrelados às permissões da coroa portuguesa quanto ao que podia ser exposto na colônia. Até então a impressão de documentos, periódicos e da produção literária não era permitida e só veio a ocorrer no início do século XIX com a vinda da Família Real portuguesa que trouxe consigo a Imprensa Real.

Muito embora acontecesse em formas de pasquins e impressões feitas na Europa e trazidas pelos estudantes revoltados com a condição colonial do país, havia aqueles que mesmo através de manuscritos e cópias reproduzidas a mão mantinham a produção literária local.

Já no século XIX com o fim da censura à imprensa vigente no Segundo Império, os autores (jornalistas, advogados, professores, intelectuais, políticos etc.) dispunham de meios para ver impressos nos jornais (e em livros) seus escritos, seus ensaios, seus romances, seus poemas. Esses mantinham suas bibliotecas particulares, assim como os conventos que mantinham suas portas fechadas para o público.

Em de 29 de outubro de 1810 é instituída oficialmente a Biblioteca Nacional, no Rio de Janeiro, cujo acervo inicial (70 mil "peças", segundo o site da Biblioteca Nacional) foi trazido por D. João VI na sua fuga ao Brasil, em razão da invasão de Portugal pelas tropas de Napoleão, em 1808, no entanto, só foi aberta ao público em 1814.

Com o desenvolvimento da literatura nacional, até mesmo com autores se destacando internacionalmente, houve outro contraponto que era o mínimo número de leitores. A educação no país ainda não era pública e mesmo quando se tornou público o acesso não era irrestrito. Escrever para quem? Produzir para quem? A maior parte da população era completamente analfabeta. 
Quando tratamos aqui de dois séculos atrás em relação à leitura parece que falamos do momento atual onde ainda se reflete que o povo brasileiro não lê, não gosta de ler, que no Brasil não temos leitores etc. $\mathrm{O}$ estímulo à produção escrita parece não acompanhar o interesse pelo grande público em ler. Portanto para que escrever e para que produzir bibliotecas em um país onde o número de analfabetismo ainda é tão grande e onde os analfabetos funcionais ainda persistem em existir?

Embora não se possa comparar a situação atual como a do Brasil Colônia, logicamente outros agravantes emperram o avanço da alfabetização e do letramento crítico no país e o incentivo à leitura e a produção escrita se perde na filosofia educacional e pedagógica ou no discurso dos professores que mandam que o aluno leia, falam da importância da leitura, mas que também não possuem o hábito de ler. .

Luckesi (2001) afirma:

Perpetua-se, hoje, embora revestida de outras circunstâncias, a realidade da "leitura" do Brasil colônia, uns poucos leem e têm reconhecido efetivamente seu direito de ler. Aos outros é usurpado este mesmo direito, tanto no atinente à leitura direta da própria realidade, quando no que se refere ao direito de se informar sobre a leitura por outros feitos sobre o mundo e os homens. (LUCKESI, 2001, p.131).

O mercado editorial brasileiro hoje em expansão, autores surgidos dos mais diferentes locais do país, maior acesso e possibilidades de impressão e veiculação, mas a queixa do não gostar de ler continua, o discurso se propaga e se repete. Embora haja diversos programas e grupos empenhados em reverter essa situação, o país ainda está longe de ser um país voltado à literatura, diferentemente dos países desenvolvidos, permanecendo a leitura inacessível a muitos grupos sociais.

Diante desse quadro, uma pergunta: para que construir mais bibliotecas? A biblioteca vai desconstruir esse quadro? A simples existência de um espaço físico diferenciado pode mudar essa perspectiva? Atualmente com as facilidades criadas pela literatura digital, uma biblioteca física faria realmente grande diferença em uma cidade?

Com o advento da internet, não são poucos os grupos de "internautas" que vêm disseminando a literatura na web. Grupos de discussão em fóruns e em comunidades das chamadas redes sociais e blogs voltados à literatura e à educação têm movimentado não apenas as discussões e críticas acerca da produção literária (nacional e internacional), mas também o mercado editorial, que vê nesse tipo crescente de discussão um meio de divulgação. Assim, pode-se dizer que há mais uma geração de leitores brasileiros, influenciada pela internet. Dizer que há uma "nova" geração de leitores pareceria equivocado, pois leitores "tradicionais" de clássicos da literatura e frequentadores de bibliotecas físicas (não apenas as virtuais) sempre existirão. (NICOLA,2007, p.132) 
Apesar dessa explosão das mídias digitais, as bibliotecas resistem e são ainda as maiores fontes de conhecimento e saber, pois são os reservatórios dos livros. Assim as funções da biblioteca pública também continuam sendo foco de discussões em vários encontros e apresentada nas mais variadas publicações da área da Ciência da Informação e de órgãos internacionais, tais como o Manifesto das Bibliotecas Públicas da UNESCO (1994).

Um dos pontos mais importantes desse documento é apresentar a biblioteca como uma asseguradora e promotora da paz e bem-estar mundial. Ainda nesse documento, a biblioteca é apresentada com as seguintes funções: assegurar o acesso à informação nos mais variados suportes informacionais e a todos os sujeitos que a solicitem; subsidiar ações e informações que permitam uma melhor (e real) participação dos sujeitos leitores nas suas ações; permitir uma ampliação dos acessos a suportes de leitura variados e as novas tecnologias; contribuir para a formação continuada dos sujeitos-leitores; contribuir para o fortalecimento da economia das comunidades que atende, principalmente da indústria editorial; e servir como um centro difusor de informações para a comunidade (URIBE TIRADO, 2007).

Infelizmente esse ideal de biblioteca existe apenas nos países onde a leitura é valorizada como parte indissociável da educação para a autonomia do homem. No Brasil ela parece uma entidade distanciada da realidade, sem laços culturais próximos, ou sem aproximação com a realidade concreta, sem falar que em muitos locais é completamente inexistente.

Trazer a proposta de criação de bibliotecas públicas para os municípios, além de fomentar as discussões para a educação e formação de leitores, abre debates para uma gama de outras temáticas que envolvem essa criação, desde o impacto cultural, social político proporcionado por essas numa cidade, bem como toda movimentação estratégica que a construção de uma biblioteca supõe.

A própria desconstrução do mito de que o brasileiro não gosta de ler pode ser fato a ser trabalhado com essa construção.

Existe um constante processo de reflexão na Ciência da Informação acerca da situação
de paradoxo que ocorre em nosso país quando se discute as bibliotecas públicas,
retomando a postulação de um espaço com pouca identificação com os sujeitos-
leitores brasileiros, decorrente de um processo histórico continuo que marca o os
brasileiros como pouco afeitos a gostar de ler, onde a biblioteca pública contribuiu de
maneira significativa para a pouca aproximação de leitores, temos no Brasil ainda um
leitor em processo de formação e aproximação com ela, que no país enfrenta uma série
de dificuldades para aproximar-se dela, incluindo a ausência de bibliotecas de todo
tipo (LAJOLO; ZILBERMAN, 2003; INSTITUTO PRÓ-LIVRO, 2007).

A leitura, enquanto objeto para formação humana é um instrumento de conhecimento do outro e de autoconhecimento, isso ocorre porque a ficção, ao mesmo tempo em que desvela a realidade, mostra que outras realidades são possíveis, libertando o leitor de seu contexto 
estreito e desenvolvendo nele a capacidade de imaginar, que é uma necessidade humana e pode gerar transformações históricas; porque a poesia capta o nível de percepção e de fruição da realidade que outros tipos de texto não alcançam (PERRONE-MOISÉS, 2008).

Quando se refere aqui a transformações históricas geradas pela leitura, remete-nos aqui à validade e função desse projeto que acredita no potencial que uma biblioteca pública pode trazer à cidade. A leitura aqui não é a decodificação de signos, mas é a leitura de mundo que nos permite essa observação.

No caso dos estudantes, por exemplo, quando servidos de uma biblioteca em suas escolas, essas são sucintas, desorganizadas, com acervos paupérrimos e não dão acesso à comunidade em geral. Ou seja, as políticas educacionais nem atendem esse requisito para a formação escolar, nem as políticas públicas valorizam e investem na criação de bibliotecas públicas.

De acordo com Milanesi (2002) a ausência da biblioteca pública contribuiu ainda com uma questão muito significativa dentro da cultura brasileira: o uso primordial dos meios de comunicação de massa, com destaque para o rádio e televisão como fonte de informação isso se dá devido à necessidade de obter informações, a ausência de políticas públicas que fomentassem a adequação, crescimento e instalação de bibliotecas públicas nas cidades do país, além de a biblioteca existente contar com a falta de preparo dos profissionais em atender o grande número de analfabetos do país, assim, "a informação dos livros, tornou-se uma obrigação aborrecida, a informação da mídia buscava o prazer para garantir a audiência" (MILANESI, 2002, p. 46).

Logicamente essa situação ficou mais agravada com as mídias digitas e acesso a internet. Segundo o INSTITUTO PRÓLIVRO (2007) o número de livros lidos no país é de 4,7 por ano, sendo que 3,4 é realizado durante o período escolar enquanto apenas 1,3 é realizado fora das escolas. Temos realidades distintas no país: na Região Norte a média é de 3,9, sendo que 3,7 são realizados na escola, enquanto 0,2 são feitos fora da escola; no Nordeste 4,2 é a média, sendo que 3,6 nas escolas e 0,6 fora delas; 4,9 é a média do Sudeste, sendo que 3,0 é na escola e 1,9 fora dela; no Sul a leitura média é de 5,5, enquanto 3,7 é na escola e 1,8fora dela; a região Centro-Oeste é de 4,5 livros, enquanto 3,4 na escola e 1,1 fora dela (INSTITUTO PRÓ-LIVRO, 2007).

Existe um número elevado de analfabetos em nosso país, cerca de 35 milhões de pessoas, a maioria dos não leitores é proveniente das classes mais pobres. O não saber ler está claramente ligado à uma concepção colonialista do não acesso ao seu padrão de leitura. E, apesar das discussões mais atuais sobre o fato de que todos de alguma forma leem e sabem ler, 
ainda é mais forte o apelo da leitura escrita convencional, pois a sua ausência, como nos tempos coloniais, significa a exclusão social do indivíduo a sua pouca apreensão ou pouco acesso continua sendo exclusão. Fica claro que numa sociedade altamente excludente e de discursos ideologicamente ambíguos, existe a clara intencionalidade de não promover o acesso à leitura plena, sob o discurso de acesso total à educação.

Essa situação complica-se com a ausência de espaços efetivos de leitura e torna-se impraticável com a estrutura vigente, em que inexistem bibliotecas escolares nas escolas e, quando existem, repetem práticas domesticadoras as quais impedem os movimentos de deslocamento dos sujeitos, o diálogo entre eles e com os livros; tudo isso tem efeitos na forma de os discursos circularem e de os sujeitos constituírem.

\begin{abstract}
A ausência de bibliotecas impede a formação de sujeitos-leitores, quando saem da escola ao invés de continuarem a buscar a leitura e efetivarem-se como leitores, acaba por afastá-los, criando neles uma ojeriza da leitura, resultando num desejo dos adultos de se livrar dos livros e do sentido de enfado que eles causam. Assim, a escola (incluindo aqui a importância da ausência das bibliotecas escolares) acaba não cumprindo a tarefa de 'seduzir' os sujeitos para a leitura, pós-muros das escolas e término do ensino médio básico. (ZILBERMAN, 2003; INSTITUTO PRÓ-LIVRO, 2008).
\end{abstract}

Assim sendo, a ausência das bibliotecas impede a formação de leitores e sujeitos independentes, que acabam ignorando a os efeitos de leitura em suas atividades cotidianas e a relação disso tudo com as questões políticas.

Discutir a problemática da biblioteca como foi dito na proposição do capítulo perpassa por questões culturais, políticas, econômicas e sociais, pois trata, sobretudo na forma como a leitura é trabalhada de modo a silenciar o sujeito. Leitura é sinônimo de libertação, autonomia dos sujeitos e pelo efeito ideológico que ela evidencia, a biblioteca é o passaporte de acesso a essa libertação.

O conceito contemporâneo de bibliotecas públicas pautado nos pressupostos de democratização do saber, cidadania e inclusão. Com os pressupostos da Modernidade e principalmente a partir do Iluminismo e das seguintes Revoluções com a popularização do conceito de cidadania, uma nova ideia de biblioteca vai se formando: a biblioteca pública e voltada para o cidadão.

O conceito de democracia e cidadania ao longo do período moderno, tem um estreito relacionamento com a emergência e consolidação do Estado liberal e do modelo de economia de mercado nas sociedades modernas ocidentais, como decorrência direta das Revoluções burguesas havidas no final do século XVIII e do desenvolvimento do modo de produção capitalista. 
Assim, com o maior desenvolvimento das sociedades capitalistas no final do século XIX, o conceito originário de democracia é identificado pela prática da democracia liberal, o que transforma de acordo com (AVRITZER, 2002), os três conceitos originários de democracia (comunidade, liberdade e igualdade) da seguinte forma:

(i) a comunidade não é mais definida pela medida comum (liberdade) e passa a ser
definida como comunidade nacional; (ii) a liberdade se define pela propriedade ( $1^{\text {a }}$
fase da democracia liberal é caracterizada pela qualificação da vontade e do
representante por sua renda, com a exclusão dos dependentes), e (iii) a igualdade se
define pela cidadania, determinada pela lei (determinando homens mais iguais,
fazendo com que discriminaçães econômicas, de raça e de sexo não sejam
incompatíveis com a igualdade).

Partindo dessa ideia hipoteticamente e moral e eticamente aquilo que separava os homens em classes ou castas, não poderia mais impedir que o acesso ao conhecimento chegasse por tal motivo.Nesse sentido a biblioteca passa a ser um patrimônio público acessível e universal, para o homem, cidadão e principalmente o agora consumidor. O consumo que marca as relações do período inaugurado na modernidade retira o homem da situação de sujeito para a situação de objeto de consumo "Quando o Estado reconhece a prioridade e superioridade das leis do mercado sobre as leis da pólis, o cidadão transforma-se em consumidor" (BAUMAN, 2000, p. 59).

O cidadão passa a ser o sujeito cada vez mais individualista, pensando em seus próprios ganhos, enquanto aceita cada vez menos a necessidade de participar no governo do Estado. Aumenta a distância entre o ideal de democracia e a sua versão real existente. O que interessa ao cidadão é o consumo próprio, reduzindo-se o mundo a uma gigantesca loja de departamentos, com prateleiras cheias das mais variadas ofertas.

Nesse sentido o aprender, o adquirir conhecimento passa a ser uma mercadoria a ser adquirida por esse cidadão e por isso precisa estar disponibilizada pela educação no âmbito público e por esse motivo as bibliotecas públicas passam a ser também um lócus desse tipo de consumo e mais, o acesso à informação passa a ser um direito constituído.

O Manifesto Em Defesa Da Biblioteca Pública elaborado pela Federação Internacional das Associações de Bibliotecários e de Bibliotecas (IFLA) e aprovado pela UNESCO em novembro de 1994. prega que a liberdade, a prosperidade e o progresso da sociedade e dos indivíduos são valores humanos fundamentais. Afirma que esses só serão atingidos quando os cidadãos estiverem na posse das informações que lhes permitam exercer os seus direitos democráticos e ter um papel activo na sociedade.

O cidadão aqui é aquele que consome o conhecimento e como lá na Antiguidade o conhecimento continua sendo símbolo de poder. Assim, o desenvolvimento da democracia e 
uma participação maciça do povo nas decisões dependem tanto de uma educação satisfatória como de um acesso livre e sem limites ao conhecimento, ao pensamento, à cultura e à informação.

A biblioteca pública é considerada a porta de acesso ao conhecimento que é a via que fornece as condições básicas para a aprendizagem ao longo da vida, para uma tomada de decisão independente e para o desenvolvimento cultural do indivíduo e dos grupos sociais. A UNESCO através do Manifesto declara a confiança que deposita na Biblioteca Pública, enquanto força viva para a educação, cultura e informação, e como agente essencial para a promoção da paz e do bem-estar espiritual através do pensamento dos homens e mulheres. Assim, a UNESCO encoraja as autoridades nacionais e locais a apoiar ativamente e a comprometerem-se no desenvolvimento das bibliotecas públicas.

A leitura tem um papel preponderante nesse contexto, uma vez que para a consolidação de uma sociedade da informação e do conhecimento, a democratização da leitura é fundamental. Questões como essas devem ser pensadas pela Arquitetura e se fazem essenciais para que além da questão da aquisição do conhecimento implícito, as bibliotecas públicas se tornem locais de interação, inclusão como foi dito em capítulo anterior.

De acordo com o mesmo Manifesto (1994) e transcrito na íntegra temos as seguintes missões-chave, relacionadas com a informação, a literacia, a educação e a cultura deverão ser a essência dos serviços da biblioteca pública:

- Criar e fortalecer hábitos de leitura nas crianças, desde a primeira infância;

- Apoiar a educação individual e a autoformação, assim como a educação formal a todos os níveis;

- Oferecer possibilidades de um criativo desenvolvimento pessoal;

- Estimular a imaginação e criatividade das crianças e jovens;

- Promover o conhecimento sobre a herança cultural, o apreço pelas artes e pelas realizações e inovações científicas;

- Facilitar o acesso às diferentes formas de expressão cultural das manifestações artísticas;

- Fomentar o diálogo inter-cultural e, em especial, a diversidade cultural;

- Apoiar a tradição oral; Assegurar o acesso dos cidadãos a todos os tipos de informação à comunidade;

- Proporcionar serviços de informação adequados às empresas locais, associações e grupos de interesse; 
- Facilitar o desenvolvimento da capacidade de utilizar a informação e a informática;

- Apoiar, participar e, se necessário, criar programas e actividades de alfabetização para os diferentes grupos etários.

Os serviços da biblioteca pública devem, por princípio, ser gratuitos. A biblioteca pública é da responsabilidade das autoridades locais e estatais. Deve ser objecto de uma legislação específica e financiada pelos governos nacionais e locais. Tem de ser uma componente essencial de qualquer estratégia a longo prazo para a cultura, o acesso à informação, a literacia e a educação.

Para assegurar a coordenação e cooperação das bibliotecas, a legislação e os planos estratégicos devem ainda definir e promover uma rede nacional de bibliotecas, baseada em padrões de serviço previamente acordados. A rede de bibliotecas públicas deve ser criada em relação com as bibliotecas nacionais, regionais, de investigação e especializadas, assim como com as bibliotecas escolares e universitárias.

De acordo com o Manifesto, deve ser formulada uma política clara, definindo objectivos, prioridades e serviços, relacionados com as necessidades da comunidade local. A biblioteca pública deve ser eficazmente organizada e mantidos padrões profissionais de funcionamento. Deve ser assegurada a cooperação com parceiros relevantes, por exemplo, grupos de utilizadores e outros profissionais a nível local, regional, nacional e internacional.

Os serviços têm de ser fisicamente acessíveis a todos os membros da comunidade. Isto pressupõe a existência de edifícios bem situados, boas condições para a leitura e o estudo, assim como o acesso a tecnologias adequadas e horários convenientes para os utilizadores. Implica igualmente serviços destinados àqueles a quem é impossível frequentar a biblioteca.

Os serviços da biblioteca devem ser adaptados às diferentes necessidades das comunidades das zonas urbanas e rurais. O bibliotecário é um intermediário activo entre os utilizadores e os recursos disponíveis. A formação profissional contínua do bibliotecário é indispensável para assegurar serviços adequados. Têm de ser levados a cabo programas de formação de utilizadores de forma a fazê-los beneficiar de todos os recursos.

Aos que têm poder de decisão, a nível nacional e local, e à comunidade bibliotecária, em todo o mundo, pede-se que apliquem os princípios expressos no presente Manifesto. Entende-se a partir daí que existe uma relação entre o que diz a missão da biblioteca pública: oferecer serviços com base na disseminação da informação, cultura e do conhecimento. A biblioteca pública se caracteriza como um local de construção permanente de cultura, uma vez que permite a aprendizagem permanente, conforme o Manifesto.

De acordo com Bernardino e Sualden (2011): 
A biblioteca como lugar de interação entre a leitura e o leitor, conservação e preservação da memória, mas, sobretudo, uma interseção entre esta e seus leitores e principalmente para estes, sejam dedicados todos os seus esforços, tanto no que diz respeito à organização e tratamento da informação como à disseminação da cultura. Uma biblioteca que atue como centro fomentador e gerador do conhecimento, como o próprio manifesto diz: porta aberta para o conhecimento.

Esses são os pressupostos contemporâneos para uma biblioteca pública e o que se espera dela, além de seu espaço físico adequado e com identidade apropriada, um espaço que e onde a informação e o conhecimento sejam além de uma responsabilidade social conjunta, atenda também aos anseios da comunidade, e onde o público atendido perceba ali um espaço democrático de valorização ao conhecimento e ao saber.

\section{CONSIDERAÇÕES FINAIS}

O crescente uso das tecnologias da informação e comunicação no cotidiano da maior parte das pessoas tornou a biblioteca pública uma fonte secundário ou quem sabe terciária como fonte de acesso à informação .O comodismo que as mídias digitais com acesso a internet trazem diminui a cada dia a procura pela biblioteca tradicional que salvo esforço de alguns por uma reformulação certamente poderá deixar de existir.

De acordo com Suaiden (2000) inserida em uma sociedade com enormes contradições sociais, a biblioteca pública deixa de cumprir seu papel primordial de ser o grande disseminador de informação Além dos tradicionais objetivos, a nova organização social demanda novas necessidades informacionais e de inclusão digital, demandas que antes não lhe eram pertencentes. E aí reside a grande crise que perpassa a biblioteca pública no Brasil, que ameaça a sua existência.

É importante que se reafirme o papel da biblioteca pública como instituição social imprescindível ao desenvolvimento democrático da sociedade e como lócus primordial entre outras instituições públicas com a missão social de reduzir as desigualdades sociais de acesso à informação e na educação.

Para tanto faz-se necessário construir um novo modelo de biblioteca que siga os parâmetros da sociedade informacional, promovendo a inclusão social e digital que possibilite a solução de problemas do cotidiano para o cidadão. As novas tecnologias apontam para a necessidade além de um letramento informacional, a viabilização da utilização dos diversos serviços que atualmente são disponibilizados pela tecnologia e que isso aconteça de maneira igualitária e atendendo aos pressupostos democráticos e cidadãos citados pelo Manifesto da Unesco. 
É preciso reafirmar a biblioteca pública como espaço de interação, interatividade, de produção e aquisição de saberes e produção de cultura. Nessa perspectiva é preciso que se construam novas bibliotecas e é preciso que se retroalimente as já construídas e se reformem aquela s que precisam. E é mister que esse espaço seja público, acessível e um difusor dos saberes como pensado desde os primórdios.

\section{REFERÊNCIAS}

ARRUDA, Guilhermina Melo. As práticas da biblioteca pública a partir das suas quatro funções básicas. In: CONGRESSO BRASILEIRO DE BIBLIOTECONOMIA E DOCUMENTAÇÃO, 19., 2000, Rio Grande do Sul.Anais... Rio Grande do Sul: PUCRS, 2000.

BARRETO, Aldo de Albuquerque. Uma história da ciência da informação. In: TOUTAIN, L. M. B. B. (Org.). Para entender a ciência da informação. Salvador: EDUFBA, 2007.

CHARTIER, Roger. Do códige ao monitor: a trajetória do escrito. Estud. av. 1994, vol.8, n.21, pp. 185-199. ISSN 0103-4014.).

FAULKNER-BROWN, Harry. Design de Grandes edifícios para Bibliotecas. In: INSTITUTO BRASILEIRO DE INFORMAÇÃOE TECNOLOGIA. A informação: tendências para o novo milênio. Brasília, DF: 1999.

INSTITUTO PRÓ-LIVRO. Retratos da leitura no Brasil. Instituto Pró-Livro, 2007.

JARAMILLO, O.; RÍOS, M.M.; TIRADO, A.U. La biblioteca pública: su gestión en el contexto de la sociedad de la información. Buenos Aires: Alfagrama, 2008. (Biblioteca Alfagrama).

LAJOLO, Marisa; ZILBERMAN, Regina. A formação da leitura no Brasil. São Paulo: Ática, 2003.

LEMOS, Charlene Kathlen. Bibliotecas comunitárias em regiões de exclusão social na cidade de São Paulo: estudo de caso da biblioteca comunitária Solano Trindade. 2005. $151 \mathrm{f}$. Trabalho de Conclusão de Curso (Graduação em Biblioteconomia)-Departamento de Ciência da Informação, UNESP, Marília, 2005.

LUCKESI C., Barreto E, Cosma , Baptista N, Fazer Universidade: uma proposta metodológica, Cortez Editora, São Paulo, 2005, 14 edição, 232 páginas.

MARTINS, Wilson. A palavra escrita: história do livro, da imprensa e da biblioteca. São Paulo: Editora Ática, 2002. 
MANGUEL, A. A biblioteca à noite. Trad. Samuel Titan Jr. São Paulo: Companhia das Letras, 2006.

MANIFESTO DA IFLA/UNESCO sobre bibliotecas públicas, 1994. Disponívelem: http://archive.ifla.org/VII/s8/unesco/port.htm . Acesso em: 20 jun. 2018.

MILANESI, L. Biblioteca. São Paulo: Ateliê Editorial, 2002.

. O que é biblioteca. São Paulo: Brasiliense, 1983. (Primeiros Passos, 94).

NICOLA, José de. Literatura Brasileira: das origens aos nossos dias. São Paulo: Scipione,2007.

PERRONE-MOISÉS, Leyla. O ensino da literatura. In: NITRINI, Sandra et al (Orgs.). Literaturas, artes, saberes. São Paulo: Aderaldo \& Rothschild: ABRALIC, 2008, p. 13-22

URIBE TIRADO, Alejandro.Los bibliotecólogos colombianos y la adquisición de competencias: Énfasis y tendencias en la actual formación en Tecnologías de la Información y la Comunicación. Rev. Interam. Bibliot [online]. 2007, vol.30, n.1, pp.135166. ISSN 0120-0976.

SANTOS, Josiel Machado. O processo histórico evolutivo das bibliotecas da Antiguidade ao Renascimento. Vida de Ensino, Goiás, v. 1, n. 1, p. 01-10, ago./fev. 2009/2010. Disponível em: $\quad<$ http://rioverde.ifgoiano.edu.br/periodicos/index. php/vidadeensino/article/view/58/40>. Acesso em 11 de setembro de 2018.

SCHWARCZ. Lília M. A Longa Viagem da Biblioteca dos Reis - Do terremoto de Lisboa à Independência do Brasil. Companhia das Letras, 2002.

SUAIDEN, Emir José. A Biblioteca Pública no Contexto da Sociedade da Informação. Ciência da Informação, Brasília, v.29, n.2, agosto 2000.

VERGER, Jacques. Os livros na idade média, tradução de Carlota Boto, referente ao capítulo III da obra Homens e Saber na Idade Média (Bauru/SP: Edusc, 1999), 